Marie S. O'Neill • Shakoor Hajat •

Antonella Zanobetti • Matiana Ramirez-Aguilar •

Joel Schwartz

\title{
Impact of control for air pollution and respiratory epidemics on the estimated associations of temperature and daily mortality
}

Received: 15 June 2005 / Revised: 6 April 2005 / Accepted: 12 April 2005 / Published online: 24 May 2005

(C) ISB 2005

\begin{abstract}
We assessed the influence of control for air pollution and respiratory epidemics on associations between apparent temperature (AT) and daily mortality in Mexico City and Monterrey. Poisson regressions were fit to mortality among all ages, children (ages 0-14 years) and the elderly (ages $\geq 65$ years). Predictors included mean daily AT, season, day of week and public holidays for the base model. Respiratory epidemics and air pollution (particulate matter $<10 \mu \mathrm{m}$ in aerodynamic diameter and $\mathrm{O}_{3}$ ) were added singly and then jointly for a fully adjusted model. Percent changes in mortality were calculated for days of relatively extreme temperatures [cold $\left(10-11^{\circ} \mathrm{C}\right)$ for both cities and heat $\left(35-36^{\circ} \mathrm{C}\right)$ for Monterrey], compared to days at the overall mean temperature in each city $\left(15^{\circ} \mathrm{C}\right.$ in Mexico City, $25^{\circ} \mathrm{C}$ in Monterrey). In Mexico City, total mortality increased $12.4 \%$ [ $95 \%$ confidence interval (CI) $10.5 \%$, $14.5 \%$ ] on cold days (fully adjusted). Among children, the adjusted association was similar [10.9\% (95\% CI: 5.4\%, $16.7 \%$ )], but without control for pollution and epidemics, was nearly twice as large [19.7\% (95\% CI: 13.9\%, 25.9)]. In Monterrey, the fully adjusted heat effect for all deaths was $18.7 \%$ (95\% CI: $11.7 \%, 26.1 \%$ ), a third lower than
\end{abstract}

\author{
M. S. O’Neill $(\bowtie)$ \\ Department of Epidemiology, University of Michigan, \\ 1214 S. University, \\ Ann Arbor, MI 48104, USA \\ e-mail:marieo@umich.edu \\ S. Hajat \\ London School of Hygiene and Tropical Medicine, Public and \\ Environmental Health Research Unit, \\ Keppel Street, \\ London, WC1E7HT, UK
}

A. Zanobetti $\cdot$ J. Schwartz

Harvard School of Public Health, Exposure, Epidemiology, and Risk Program,

401 Park Drive Suite 415 West,

Boston, MA 02215, USA

\section{Ramirez-Aguilar}

Instituto Nacional de Salud Pública, Avenida Universidad 655,

Col. Sta. María Ahuacatitlan,

Cuernavaca, Morelos 62508, México the unadjusted estimate; the heat effect was lower among children [5.5\% (95\% CI: - 10.1\%, 23.8\%)]. Cold had a similar effect on all-age mortality as in Mexico City [11.7\% (95\% CI: 3.7\%, 20.3\%)]. Responses of the elderly differed little from all-ages responses in both cities. Associations between weather and health persisted even with control for air pollution and respiratory epidemics in two Mexican cities, but risk assessments and climate change adaptation programs are best informed by analyses that account for these potential confounders.

Keywords Temperature $\cdot$ Mortality $\cdot$ Weather $\cdot$ Air pollution $\cdot$ Mexico

\section{Introduction}

Studies conducted in diverse regions of the world have shown mortality and morbidity increases at temperature extremes, and global climate change may worsen the toll in certain areas (Whitman et al. 1997; Semenza et al. 1999; Keatinge et al. 2000; Braga et al. 2002; Hajat et al. 2002; Basu and Samet 2003). To date, the majority of research on weather and human health outcomes has been conducted in developed countries, and a limited number of studies have evaluated which people are most vulnerable to temperature extremes (Semenza et al. 1996; Curriero et al. 2002; Klinenberg 2002; Gouveia et al. 2003; O’Neill et al. 2003). The purpose of this study was to characterize associations between temperature extremes and daily mortality in two cities from a middle-income country (Mexico) and assess whether these associations differed by age and with control for air pollution, respiratory epidemics and various ways of modeling seasonal mortality trends.

\section{Materials and methods}

Study areas

Monterrey is Mexico's third largest city and is in the north in the state of Nuevo Leon (altitude 540 m); Mexico City, 
the capital and Mexico's largest city (altitude 2,240 m) is located in a valley in central Mexico. The metropolitan area of Mexico City encompasses both the country's capital city in the Federal District, and the surrounding suburbs of the State of Mexico. Both cities have semiarid climates and are major industrial centers surrounded by mountains. Metropolitan Mexico City's population has been estimated at about 18 million people and Monterrey's at approximately 1-2 million, when surrounding suburbs are included (INEGI 2004).

\section{Air pollution and weather data}

Environmental data were obtained from monitoring networks operated by the municipal governments of Mexico City and Monterrey. Daily temperature and relative humidity readings are made by automatic-recording instruments. We calculated averages from the monitors reporting on any given day for the mean of both parameters. We then converted relative humidity to dewpoint and calculated apparent temperature (AT), which represents an individual's perceived air temperature, using the following formula (Steadman 1979; Kalkstein and Valimont 1986):

$\mathrm{AT}=-2.653+(0.994 \times T \mathrm{a})+\left(0.0153 \times T \mathrm{~d}^{2}\right)$

where $T \mathrm{a}$ is air temperature and $T \mathrm{~d}$ is dew point temperature.

For both cities, 24-h average concentrations of particulate matter $<10 \mu \mathrm{m}$ in aerodynamic diameter $\left(\mathrm{PM}_{10}\right)$ and $\mathrm{O}_{3}$ were obtained, since these pollutants have been important predictors of mortality in previous studies in Mexico (Borja-Aburto et al. 1997; O'Neill et al. 2004; Romieu et al. 2004). In Mexico City, $\mathrm{PM}_{10}$ was measured hourly with the Rupprecht \& Patashnik tapered element oscillating microbalance sampler (Patashnick and Rupprecht 1991) and in Monterrey, with a beta-attenuation mass monitor (Met One Instruments) (website accessed 7 April 2004). In both cities, $\mathrm{O}_{3}$ was measured by ultraviolet photometry, and 24-h concentrations were averaged over the reporting monitors (five in Mexico City, six in Monterrey).

\section{Mortality data}

Mortality tapes from the years 1996-1998 (Mexico City) and 1996-1999 (Monterrey) were obtained on CD-ROM from the Mexican National Institute of Statistics, Geography and Information. For the analysis, we excluded deaths from external causes and included individuals who both lived and died within the two metropolitan areas. Causes of death prior to 1998 were coded according to the International Classification of Diseases (ICD) 9th revision, in which external causes are $>$ E800. Deaths occurring in 1998 and 1999 were classified according to the 10th ICD revision, with codes V01-Y89 for external causes. The fi- nal analysis dataset for Mexico City included a total of 206,468 deaths occurring from January 1996 to December 1998. For Monterrey, the total was 21,758, occurring from January 1996 to December 1999 For both Mexico City and Monterrey, we stratified the daily death counts into two broad age categories: (1) children, ages $0-15$ years; and (2) elderly, ages $\geq 65$ years.

\section{Statistical models}

Robust Poisson regression was used to model the time series from each city. We fit separate models for total and age-specific mortality for each city. We used natural cubic splines (Hastie and Tibshirani 1990; Wypij 1996), to model long-term trends in mortality, choosing the $d f$ to minimize the sum of the partial autocorrelation function (Katsouyanni et al. 1997). Autoregressive terms were added if necessary if remaining auto-correlation appeared in the partial autocorrelation function plots (Brumback et al. 2000). S-Plus 2000 (Mathsoft, Seattle, Wash.) software was used to fit the models, and a strict convergence criterion was employed to avoid problems previously identified in time-series analysis (Dominici et al. 2002).

We used a $3 d f$ curve of the mean of the previous week's AT (temperature) to capture the effect of a cold spell in both cities, and a $3 d f$ curve of the 3-day lagged moving average of temperature to capture heat effects in Monterrey. A $3 d f$ spline was adequate to capture the nonlinear relation between temperature and mortality, as assessed by comparing plots of the temperature and mortality relationship modeled with a nonparametric smoother (loess) vs. the $3 d f$ spline. Knot points were placed at equal intervals across the spline. Because previous studies have reported associations between mortality and temperature over longer exposure periods (Braga et al. 2001), we wanted to pick the lagged averaging period showing the strongest heat and cold effects, given our goal of evaluating effect modification by age. Comparing averaging periods from lag zero up to the 2 -week moving average, the cold effect was highest, then leveled off after a 1-week average, and the SE increased as longer averages were used. The heat effect was relatively insensitive to averaging times, but was highest at the 3-day moving average. We therefore selected the 1-week and 3day lagged moving averages to represent the cold and heat effects, respectively.

From the above models, the heat effect was estimated by using the model prediction at the 95th percentile increment of temperature, and the cold effect was the model estimate at the 5th percentile increment. In both cases, the predicted mortality at that $1{ }^{\circ} \mathrm{C}$ increment was contrasted to that at the $1{ }^{\circ} \mathrm{C}$ mean temperature increment for both cities. In addition, to allow comparisons between the cities, we also calculated the cold effect in Monterrey at the temperature increment corresponding to Mexico City's mean. To correct for potential extra-Poisson variation, we adjusted the SEs for over- or under-dispersion (McCullagh and Nelder 1989). The 95th percentile temperature increment 
for Mexico City was $20-21^{\circ} \mathrm{C}$, not an extreme likely to be physiologically stressful, but we calculated the effect for the base and fully adjusted models at that increment relative to the mean. The 95th percentile temperature increment for Monterrey was $35-36^{\circ} \mathrm{C}$. The cold effect for both Mexico City and Monterrey is reported at the $10-11^{\circ} \mathrm{C}$ increment. To compare the heat effect in Monterrey with that observed in five USA cities, we fit a model similar to that in a previous publication, using a lag 0 temperature term for heat, and expressing the excess mortality at the $29-30^{\circ} \mathrm{C}$ increment relative to the $15-16^{\circ} \mathrm{C}$ increment (O'Neill et al. 2003). It was not possible to do similar comparisons with the USA cities for Mexico City or for the cold effects in Monterrey because the temperature extremes observed in the USA cities were not reached in the two Mexican cities.

We wished to evaluate the sensitivity of the temperature effect to control for various factors predictive of daily mortality. All the statistical models included AT (as described previously) as well as indicator variables for day of week and public holidays, and the natural spline modeling seasonal patterns in mortality (the base model). We varied the $d f$ of the seasonal spline (doubling and halving them), an approach that was recommended in a recent re-analysis of time series studies (Health Effects Institute 2003). We also ran models with and without: a linear term for $\mathrm{PM}_{10}$ $\left(\mu \mathrm{g} / \mathrm{m}^{3}, 3\right.$-day lagged moving average for the heat models, and 1-week lagged moving average for the cold models), a linear term for $\mathrm{O}_{3}$ (p.p.b., again with moving averages corresponding to the temperature moving average), and terms to reflect respiratory epidemics, as described next.

One concern when evaluating the effects of temperature and air pollution on health outcomes is potential confounding by infectious diseases that may co-vary with those environmental variables, or be more prevalent during extreme weather when people spend more time indoors in proximity to others. In a previous study of air pollution and daily mortality, epidemic periods were defined as $\geq 10$ consecutive days on which the 3-day moving average of hospital admissions for pneumonia was higher than the 90th percentile (Braga et al. 2000). Separate polynomials were fitted to day of epidemic in each epidemic to model its rise and fall. In addition to those periods, we used indicator variables to model individual days exceeding the 90th percentile that were not part of a $\geq 10$-day "epidemic". For the present study, we had no concurrently available hospital admissions data, but used a similar approach to limit the potential for confounding of temperature effects by epidemics, substituting respiratory-cause mortality (ICD-9 codes 460-520; ICD-10 code J) for hospital admissions for pneumonia.

In addition to these main analyses, we conducted an analysis of adult and elderly mortality in Mexico to evaluate whether the temperature and mortality association differed by cause of death. Small numbers made modeling cause-specific mortality impractical for children in Mexico City and in all of Monterrey. We stratified the deaths by three major categories: cardiovascular (ICD-9 390-460 or ICD-10 cause I), respiratory (ICD-9 460-520 or ICD-10 cause $\mathrm{J}$ ), and other (all other codes).

\section{Results}

Table 1 presents the summary statistics on the environmental variables and mortality counts for Mexico City and Monterrey. Mexico City is a more polluted city than Monterrey: mean $\mathrm{PM}_{10}$ levels (24-h averages) during the study period were about $25 \mu \mathrm{g} / \mathrm{m}^{3}$ higher in Mexico City than in Monterrey, and $\mathrm{O}_{3}$ levels (24-h average) were 13 p.p.b. higher. Temperatures in Monterrey get much higher than in Mexico City, with an annual mean of $25.2^{\circ} \mathrm{C}$

Table 1 Descriptive statistics for environmental variables [apparent temperature $(A T), \mathrm{O}_{3}$, particulate matter $<10 \mu$ m aerodynamic diameter $\left.\left(P M_{10}\right)\right]$ and mortality

\begin{tabular}{|c|c|c|c|c|c|c|}
\hline City (time period) & Variable (units) & Total & Mean & Standard Deviation & Minimum & Maximum \\
\hline \multirow[t]{6}{*}{ Mexico City (1996-1998) } & Daily deaths & 206,510 & 188.6 & 30.0 & 121 & 308 \\
\hline & Deaths, $<15$ years & 27,577 & 25.3 & 6.5 & 10 & 61 \\
\hline & Deaths, $>65$ years & 105,851 & 96.7 & 19.3 & 52 & 175 \\
\hline & $\operatorname{AT}\left({ }^{\circ} \mathrm{C}\right)^{\mathrm{a}}$ & & 14.6 & 2.9 & 6.3 & 22.4 \\
\hline & $\mathrm{O}_{3}$ (p.p.b.) $)^{\mathrm{b}}$ & & 35.3 & 10.9 & 9.3 & 72.6 \\
\hline & $\mathrm{PM}_{10}\left(\mu \mathrm{g} / \mathrm{m}^{3}\right)^{\mathrm{c}}$ & & 75.8 & 31.4 & 18.0 & 233.9 \\
\hline \multirow[t]{6}{*}{ Monterrey (1996-1999) } & Daily deaths & 21,758 & 14.9 & 4.7 & 3.0 & 40.0 \\
\hline & Deaths, $<15$ years & 1,718 & 1.2 & 1.1 & 0.0 & 6.0 \\
\hline & Deaths, $>65$ years & 13,034 & 8.9 & 3.6 & 0 & 29 \\
\hline & AT $\left({ }^{\circ} \mathrm{C}\right)$ & & 25.2 & 8.5 & -2.7 & 42.1 \\
\hline & 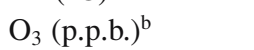 & & 23.3 & 8.1 & 2.6 & 52.6 \\
\hline & $\mathrm{PM}_{10}\left(\mu \mathrm{g} / \mathrm{m}^{3}\right)^{\mathrm{d}}$ & & 50.0 & 23.5 & 6.2 & 230.8 \\
\hline
\end{tabular}

${ }^{a}$ Average mean daily AT from ambient monitoring network (averaged from all reporting monitors)

${ }^{b} \mathrm{O}_{3}$ measured with ultraviolet photometry, 24-h average (averaged from all reporting monitors). Mexican $\mathrm{O}_{3}$ standard: 110 p.p.b. 1-h average ${ }^{\mathrm{d}} \mathrm{PM}_{10}$ measured by a beta-attenuation mass monitor (Met One Instruments) (averaged from all reporting monitors). Mexican $\mathrm{PM}_{10}$ standard: $150 \mu \mathrm{g} / \mathrm{m}^{3}$ 24-h average

Source: Compendio estadistico de la calidad del aire (1986-1999). Gobierno del Distrito Federal, Secretaria del Medio Ambiente, Direccion, General de Prevencion y Control de la Contaminacion (2000) 
Fig. 1 Time series plots of all-cause, all-age daily mortality counts and apparent temperature (AT; Temperature; ${ }^{\circ} \mathrm{C}$ ) for Mexico City and Monterrey
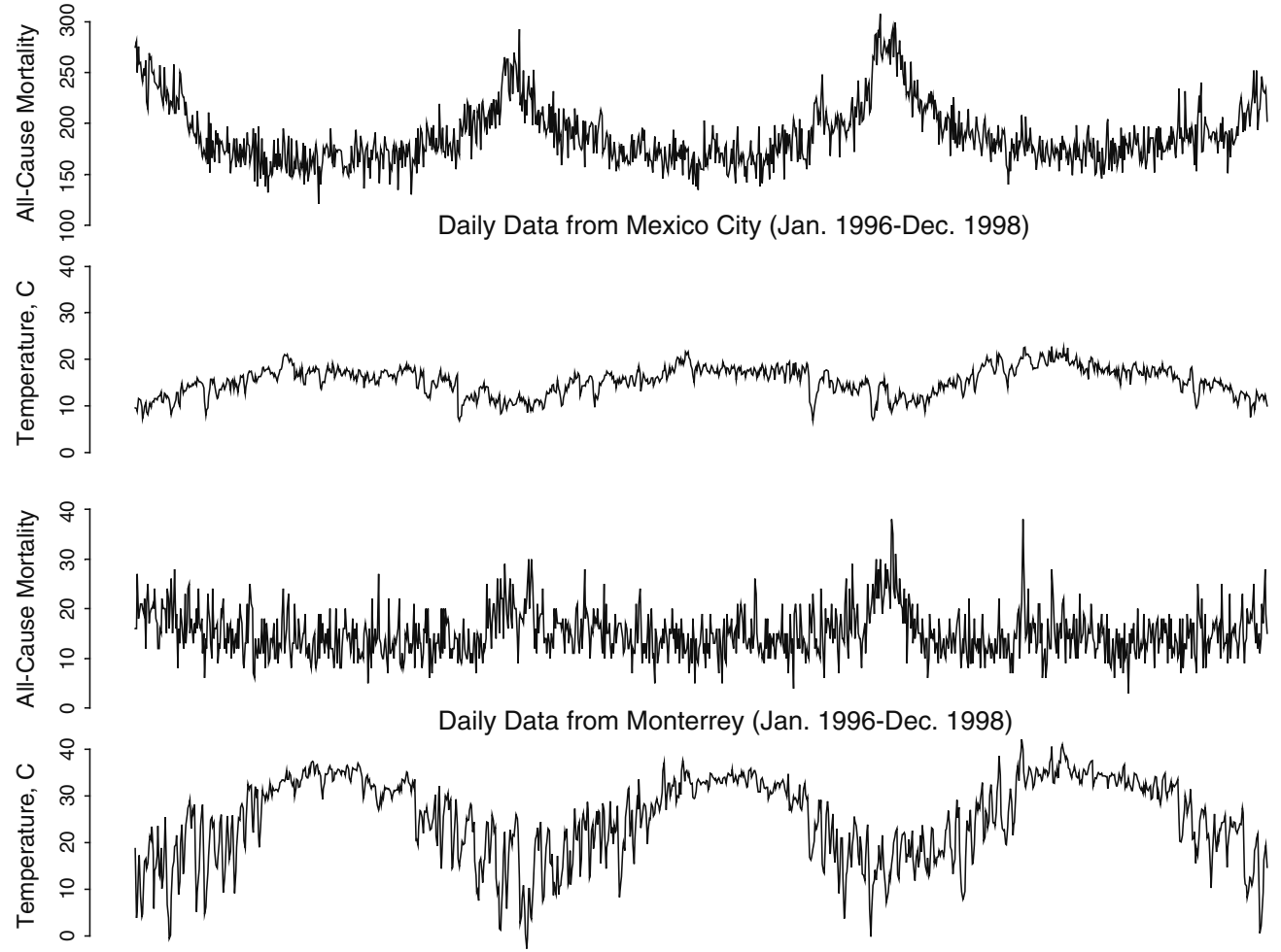

over the study period, compared to $14.6^{\circ} \mathrm{C}$ in Mexico City; Monterrey experiences a greater range of temperatures as well. The death counts in Monterrey reflect the fact that the city is roughly a tenth the size of Mexico City.

Figure 1 shows the time series of daily mortality and temperature in both of the cities, for 1996-1998, to allow comparison. The winter peaks in mortality are much greater in Mexico City than in Monterrey. This difference also appears more striking because of the tenfold difference in numbers of deaths in the Mexico City, so a threefold range in death counts across the study period represents a difference of about 200 deaths compared to around 30 in Monterrey. Temperature range in Monterrey is about twofold higher than in Mexico City, but temperature variability declines substantially in Monterrey during the summer.

Figure 2 plots the associations between temperature and mortality in both cities, controlling for public holidays, day of week, air pollution, respiratory epidemics, and long-term trends in mortality. In Mexico City, the 7-day temperature mortality association has a hockey stick shape with essentially no effect of higher temperatures, whereas in Monterrey, the spline shows a U-shape; a higher mortality risk at both ends of the distribution. Plots looked similar for the 3-day lagged moving average temperature term used to estimate heat effects, but a slight upturn on the right end
Fig. 2 Plots of the natural cubic spline $(3 d f)$ modeling the association between a 1-week lagged moving average of AT $\left({ }^{\circ} \mathrm{C}\right)$ and the log relative risk of daily, all-cause mortality. Spline is from a Poisson regression model with covariates including day of week, public holidays, respiratory epidemics, air pollution, and long-term trends in mortality, in Mexico City and Monterrey
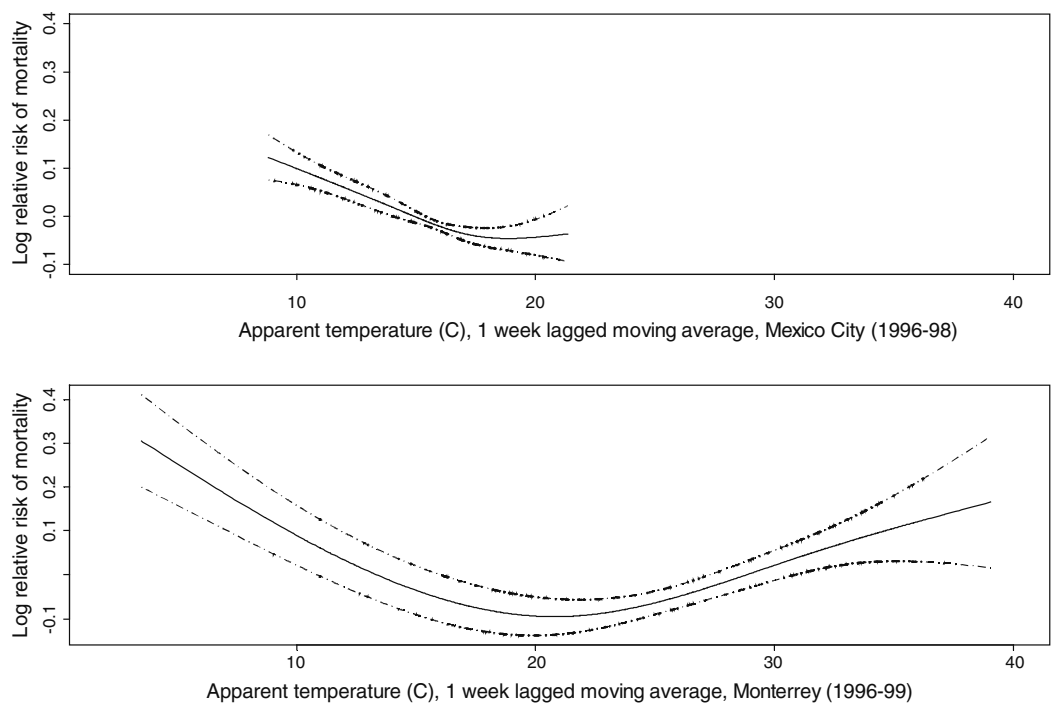
Table 2 Percent change in daily mortality and $95 \%$ confidence intervals (CIs) at $35-36^{\circ} \mathrm{C}$ AT relative to $25-26^{\circ} \mathrm{C}$ (3-day lagged moving average) by age, and under differing model specifications, Monterrey 1996-1999

\begin{tabular}{|c|c|c|c|}
\hline Model covariates & All-age mortality & Elderly ( $\geq 65$ years) & Children $(0-15$ years $)$ \\
\hline Base model: day of week, public holidays, season ${ }^{\mathrm{a}}$ & $27.2(20.0,34.7)$ & $27.5(18.3,37.5)$ & $6.6(-8.1,23.6)$ \\
\hline Base model plus $\mathrm{O}_{3}$ (moving average, lags $0-2$ ) & $25.2(18.1,32.8)$ & $26.4(17.1,36.5)$ & $7.2(-7.6,24.4)$ \\
\hline Base model plus $\mathrm{PM}_{10}$ (moving average, lags $0-2$ ) & $20.8(13.6,28.5)$ & $21.8(12.4,32.0)$ & $9.0(-6.9,27.6)$ \\
\hline Base model plus $\mathrm{O}_{3}, \mathrm{PM}_{10}$ & $20.4(13.3,28.1)$ & $21.6(12.2,31.8)$ & $9.9(-6.3,28.8)$ \\
\hline Base model plus respiratory epidemics ${ }^{b}$ & $24.5(17.6,31.8)$ & $24.4(15.5,34.0)$ & $2.1(-12.0,18.5)$ \\
\hline Base model plus $\mathrm{O}_{3}$ and epidemics & $22.4(15.5,29.7)$ & $22.9(14.0,32.6)$ & $2.9(-11.4,19.5)$ \\
\hline Base model plus $\mathrm{PM}_{10}$ and epidemics & $19.1(12.1,26.6)$ & $20.1(11.0,30.0)$ & $4.1(-11.2,22.0)$ \\
\hline Base model plus $\mathrm{O}_{3}, \mathrm{PM}_{10}$ and epidemics & $18.7(11.7,26.1)$ & $19.7(10.6,29.6)$ & $5.5(-10.1,23.8)$ \\
\hline
\end{tabular}

${ }^{\mathrm{a}} \mathrm{d} f$ for seasonal natural cubic spline are 18 for both all-age and elderly mortality, 8 for child mortality

${ }^{b}$ Natural cubic splines for periods $>10$ days with respiratory-cause mortality $>90$ th percentile, dummies for other days

of the temperature spectrum was observed for Mexico City, and a less steep slope for the cold effects (data not shown).

In Monterrey, 27.2\% higher mortality [95\% confidence interval (CI): $20.0 \%, 34.7 \%$ ] was observed on days with ATs between 35 and $36^{\circ} \mathrm{C}$ compared with days at $25-26^{\circ} \mathrm{C}$, controlling for season, day of week and public holidays (Table 2). This association was diminished but remained positive and significant when $\mathrm{O}_{3}, \mathrm{PM}_{10}$, and respiratory epidemic terms were included, singly and jointly, in the models [18.7\% excess mortality (95\% CI: $11.7 \%, 26.1 \%)]$. The reduction in the effect estimates was as much as a third, so it is evident that control for these factors is important in achieving an accurate estimate of the impact of temperature on mortality. The pollutants, both singly and jointly, had the most impact on diminishing the heat effect, whereas epidemics had little effect on the magnitude of the estimates. When the $d f$ for the seasonal smoothing spline were halved, the effect substantially diminished, for all-age mortality: $7.1 \%$ (95\% CI: 3.3\%, 11.1\%), possibly due to the fact that mortality tends to peak in the winter in Monterrey. Doubling the $d f$ changed the estimate very little.

When mortality counts were stratified by age, the effects of heat on daily mortality among those aged $\leq 15$ years were substantially lower than among those $\geq 65$ years, though sparse data made the estimates very imprecise (Table 2 ). The estimates among those older than 65 years were not very different from the estimates for all-age mortality. Similar to all-age mortality, the age-specific heat effects were somewhat sensitive to the choice of covariates and extent of smoothing with the seasonal spline, but remained positive and significant among the elderly for all model specifications tested.

To compare the heat effects in Monterrey with those observed in five USA cities, we fitted a model similar to that used in previous analysis (O'Neill et al. 2003). Lag 0 AT was used to model the effects of heat at $29-30^{\circ} \mathrm{C}$ compared to the $15-16^{\circ} \mathrm{C}$ increment, controlling for $\mathrm{PM}_{10}$, seasonal trends, day of week, and a moving average of temperature at lags 1-3. Using this model, the heat effect in Monterrey was, for all-age mortality, $7.3 \%$ (95\% CI: $4.8 \%, 9.8 \%$ ), and among elderly people $7.1 \%$ (95\% CI: $3.9 \%, 10.4 \%$ ). These estimates were within the range seen in the five USA cities (0.5-12.3\% for all ages and 2.5-8.7\% for the elderly).

In Monterrey, 9.8\% higher (95\% CI: 3.6\%, 16.5\%) allage mortality was seen on days when the previous weekly mean temperature was between 10 and $11^{\circ} \mathrm{C}$, compared with 25 and $26^{\circ} \mathrm{C}$, controlling for season, day of week and public holidays (Table 3 ). This estimate was approximately doubled when $9 d f$ were used to model seasonal mortality trends [22.9\% (95\% CI: 17.9\%, 28.2\%)], but otherwise was little affected by adjustment for differing covariate specifications. In the fully controlled model, the effect was very slightly higher [11.7\% (95\% CI: 3.7\%, 20.3\%)], but not

Table 3 Percent change in daily mortality and $95 \%$ CIs at $10-11{ }^{\circ} \mathrm{C}$ AT relative to $25-26^{\circ} \mathrm{C}$ (7-day lagged moving average) by age, and under differing model specifications, Monterrey 1996-1999. For abbreviations, see Tables 1 and 2

\begin{tabular}{|c|c|c|c|}
\hline Model covariates & All-age mortality & Elderly ( $\geq 65$ years) & Children ( $0-15$ years $)$ \\
\hline Base model: day of week, public holidays, season ${ }^{\mathrm{a}}$ & $9.8(3.6,16.5)$ & $8.0(-0.2,16.8)$ & $12.8(-4.7,33.5)$ \\
\hline Base model relative to $15-16^{\circ} \mathrm{C}$ & $7.8(1.4,14.6)$ & $5.8(-7.6,8.2)$ & $9.7(-7.3,29.8)$ \\
\hline Base model plus $\mathrm{O}_{3}$ (moving average, lags $0-6$ ) & $12.7(5.9,19.9)$ & $9.5(0.9,18.8)$ & $11.3(-6.3,32.1)$ \\
\hline Base model plus $\mathrm{PM}_{10}$ (moving average, lags 0-6) & $13.4(6.0,21.4)$ & $10.9(1.6,21.2)$ & $9.8(-7.8,30.8)$ \\
\hline Base model plus $\mathrm{O}_{3}, \mathrm{PM}_{10}$ & $14.4(6.8,22.4)$ & $11.5(2.0,21.9)$ & $9.7(-8.1,30.9)$ \\
\hline Base model plus respiratory epidemics ${ }^{b}$ & $8.7(1.6,16.3)$ & $5.1(-3.7,14.7)$ & $19.3(-2.2,45.7)$ \\
\hline Base model plus $\mathrm{O}_{3}$ and epidemics & $10.7(3.3,18.6)$ & $6.6(-2.5,16.6)$ & $17.9(-3.7,44.3)$ \\
\hline Base model plus $\mathrm{PM}_{10}$ and epidemics & $11.0(3.1,19.5)$ & $6.7(-3.1,17.5)$ & $15.3(-6.3,41.8)$ \\
\hline Base model plus $\mathrm{O}_{3}, \mathrm{PM}_{10}$ and epidemics & $11.7(3.7,20.3)$ & $7.3(-2.6,18.2)$ & $15.4(-6.3,42.1)$ \\
\hline
\end{tabular}

${ }^{a} d f$ for seasonal natural cubic spline are 18 for both all-age and elderly mortality, 8 for child mortality

${ }^{\mathrm{b}}$ Natural cubic splines for periods $>10$ days with respiratory-cause mortality $>90$ th percentile, dummies for other days 
Table 4 Percent change in daily mortality and $95 \%$ CIs at $10-11^{\circ} \mathrm{C}$ AT relative to $15-16^{\circ} \mathrm{C}$ (7-day lagged moving average) by age, and under differing model specifications, Mexico City 1996-1998. For abbreviations, see Tables 1 and 2

\begin{tabular}{|c|c|c|c|}
\hline Model covariates & All-age mortality & Elderly ( $\geq 65$ years) & Children ( $0-15$ years $)$ \\
\hline Base model: day of week, public holidays, season ${ }^{\mathrm{a}}$ & $9.9(7.8,12.1)$ & $7.7(4.8,10.6)$ & $19.7(13.9,25.9)$ \\
\hline Base model plus $\mathrm{O}_{3}$ (moving average, lags $0-6$ ) & $10.0(7.9,12.2)$ & $7.8(4.9,10.8)$ & $19.2(13.2,25.5)$ \\
\hline Base model plus $\mathrm{PM}_{10}$ (moving average, lags 0-6) & $10.3(8.2,12.5)$ & $7.8(4.9,10.7)$ & $20.8(14.8,27.1)$ \\
\hline Base model plus $\mathrm{O}_{3}, \mathrm{PM}_{10}$ & $10.2(8.1,12.4)$ & $7.8(4.9,10.8)$ & $20.1(14.1,26.4)$ \\
\hline Base model plus respiratory epidemics ${ }^{\mathrm{b}, \mathrm{c}}$ & $12.0(10.1,14.0)$ & $11.5(8.9,14.2)$ & $10.5(5.1,16.2)$ \\
\hline Base model plus $\mathrm{O}_{3}$ and epidemics ${ }^{\mathrm{c}}$ & $12.3(10.3,14.3)$ & $11.7(9.0,14.5)$ & $10.7(5.2,16.5)$ \\
\hline Base model plus $\mathrm{PM}_{10}$ and epidemics ${ }^{\mathrm{c}}$ & $12.4(10.4,14.4)$ & $11.6(8.9,14.4)$ & $10.9(5.4,16.7)$ \\
\hline Base model plus $\mathrm{O}_{3}, \mathrm{PM}_{10}$ and epidemics ${ }^{\mathrm{c}}$ & $12.4(10.5,14.5)$ & $11.7(9.0,14.5)$ & $10.9(5.4,16.7)$ \\
\hline
\end{tabular}

${ }^{a} 15 d f$ for seasonal spline for all age categories; autoregressive (AR) terms needed for all-age, elderly

${ }^{\mathrm{b}}$ Modeled as natural cubic splines for periods with $\geq 10$ days with respiratory-cause mortality $>90$ th percentile

${ }^{\mathrm{c}}$ Seasonal spline $d f$ lowered to 11 for all-age, elderly; $10 d f$ for child mortality; AR term no longer needed for all-age model

significantly so. Child mortality was higher than all-age or elderly mortality in the base model; but again the estimates were very imprecise. When controlling for respiratory epidemics, the effect size was doubled, but again, CIs were wide. In the case of the elderly, adjustment for respiratory epidemics almost halved the effect estimates and made them insignificant. In Monterrey, control for pollutants increased the effect for the elderly and all-age category, and decreased the effect in children. The opposite pattern was observed for epidemics.

In Mexico City, an excess of 9.9\% mortality among all ages was associated with cold temperature $(95 \% \mathrm{CI}$ : $7.8 \%, 12.1 \%$ ) all-age mortality, compared with days when the previous week's mean temperature was between 15 and $16^{\circ} \mathrm{C}$, controlling for season, day of week and public holidays (Table 4). As in Monterrey, this estimate was increased with fewer $d f$ used to model seasonal mortality trends, but otherwise was robust to covariate specifications. Child mortality was substantially higher than all-age or elderly mortality in the base model: $19.7 \%$ (95\% CI: 13.9-25.9\%). When controlling for respiratory epidemics, however, the effect size was approximately halved and did not differ significantly from effects observed in the other age categories. The child-mortality estimates were less sensitive than the other age categories to changing $d f$ for the seasonal spline. In Mexico City, adjusting for pollution had very little effect on the temperature estimates. Adjustment for epidemics increased associations for all-age and elderly mortality, and decreased them among children.

To compare the cold effects in Mexico City with those in Monterrey, we also estimated the effects in Monterrey at the same reference temperature increment $\left(15-16^{\circ}\right)$ as for Mexico City. With the fully adjusted model, the cold effect for all-age mortality in Monterrey was 8.3\% (95\% CI: $0.5 \%, 16.6 \%$ ), somewhat lower than observed at the reference increment of $25-26^{\circ} \mathrm{C}$. Similarly, the effects were lower among elderly people, at the Mexico City reference temperature, and for the unadjusted model, but generally similar in magnitude to those seen in Mexico City.

We also estimated the effect of "heat" at $20-21^{\circ}$ in Mexico compared to $15-16^{\circ} \mathrm{C}$, for all-age and elderly mortality, in the fully adjusted model. Among the elderly, the association was an increase of 3.5\% (95\% CI: 0.3\%, 6.9\%), and for all-age mortality, the association was $0.3(95 \%$ CI: $-2.0 \%, 2.7 \%)$. These modest effects are consistent with the plots showing only a slight increase in mortality at the highest end of the temperature spectrum in Mexico City.

In Mexico City, cardiovascular-cause mortality was more strongly associated with cold temperatures among the elderly (Table 5), with an $18.8 \%$ excess (95\% CI: $9.0 \%$ $14.5 \%)$. By contrast, respiratory-cause mortality was most strongly associated with cold temperatures when only adults aged 15-65 years were considered. A $16.5 \%$ excess in respiratory-cause mortality was observed $(95 \% \mathrm{CI}$ : $4.1 \%-30.5 \%$ ) compared to a $10.6 \%$ excess in all-cause mortality (95\% CI: 7.4\%-13.9\%) Cardiovascular mortality had about the same magnitude of effect as all-cause mortality. The pattern was similar among all-age mortality as for the adults.
Table 5 Percent change in daily mortality and $95 \% \mathrm{Cls}$ at $10-11^{\circ} \mathrm{C}$ AT relative to $15-16^{\circ} \mathrm{C}$ (1-week lagged moving average) by age and cause of death, Mexico City $1996-1998^{\mathrm{a}, \mathrm{b}}$. For abbreviations, see Tables 1 and 2

\begin{tabular}{llll}
\hline Cause of death & All-age mortality & Elderly $(\geq 65$ years $)$ & Adults $(15-65$ years $)$ \\
\hline All-cause & $12.4(10.5,14.5)$ & $11.7(9.0,14.5)$ & $10.6(7.4,13.9)$ \\
Cardiovascular $^{\mathrm{c}}$ & $13.8(9.9,17.8)$ & $18.8(14.5,23.3)$ & $9.3(2.4,16.8)$ \\
Respiratory $^{\mathrm{d}}$ & $21.5(15.6,27.7)$ & $9.3(2.6,16.4)$ & $16.5(4.1,30.5)$ \\
Other & $7.9(5.5,10.4)$ & $8.1(4.5,11.8)$ & $9.9(6.1,13.8)$ \\
\hline
\end{tabular}

${ }^{\text {a}}$ From models controlling for day of week, public holidays, season, $\mathrm{O}_{3}, \mathrm{PM}_{10}$ and epidemics ${ }^{\mathrm{b}} d f$ for seasonal natural cubic spline ranged from 8 to 11 , based on partial autocorrelation function 'International Classification of Diseases (ICD)-9 390-460; ICD-10 cause I

'ICD-9: 460-520; ICD-10 cause J 


\section{Discussion}

We observed significant excess mortality on hot and cold days in Monterrey and Mexico City. These associations persisted even when controlling for the effects of air pollution, respiratory epidemics, and season. However, failure to control for respiratory epidemics and air pollution resulted in an overestimate of the impact of hot days by $50 \%$. This has important implications for risk assessment. Most previous assessments of effects of heat waves on hot days have not controlled for air pollution or epidemics. By contrast, control for these factors had little impact on the estimates of effect of cold days. The exception was mortality in children, where cold-day mortality estimates did appear to be confounded by respiratory epidemics and air pollution in Mexico City. When these epidemics were taken into account, all age groups were affected about equally by cold temperatures in Mexico City. The effects of cold weather on all-age mortality were similar in Monterrey and Mexico City.

The data for this study were compiled as part of a larger collaboration to examine associations between temperature and mortality in cities of low and middle income countries (Wilkinson et al. 2002) and our results contribute new understanding of population responses to temperature extremes. An important motivation of this research is the phenomenon of global climate change, which is resulting in both increased global average temperatures as well as increased variability in weather patterns (Karl et al. 1995; Easterling et al. 2000; Houghton et al. 2001). Because cities in lower and middle income countries such as Mexico have limited resources to adapt to climate change, quantifying the impacts of temperature extremes on these populations (not just characterizing the dose-response) can provide important information on the potential health and economic impacts of control strategies.

The effects observed in this study are consistent with the body of literature showing excess mortality associated with both heat (Basu and Samet 2003) and cold (Braga et al. 2002; Curriero et al. 2002; O'Neill et al. 2003). The majority of previous studies were conducted in Europe and North America, where population and housing profiles differ from lower income countries such as Mexico and Brazil. In the present analysis, only Monterrey had heat extreme enough to allow a quantitative comparison with five North American cities; associations with mortality were quite similar, among these cities, in spite of probable differences in population and housing characteristics. One recent study evaluated the association between temperature and mortality in Sao Paulo, Brazil, and found that increased mortality occurred at both extremes (hot and cold) of the temperature spectrum, with slightly weaker effects among the elderly compared to other age groups (Gouveia et al. 2003). Though a different modeling approach was used from the present report, (calculating excess percent mortality per degree above or below $20^{\circ} \mathrm{C}$ ), these results and ours show that even in more temperate climates such as those in Brazil and Mexico, excess mortality is observed at extremes of the temperature spectrum. Temperatures of $10-11^{\circ} \mathrm{C}$ are not very cold, and temperatures of $20-21^{\circ} \mathrm{C}$ are not very hot, suggesting the importance of local conditions in determining health response to weather, as some excess in mortality was observed in Mexico City, relative to the mean, at these temperature increments. People tend to acclimate to the commonly experienced range of temperature, so slight departures from this range may cause physiological stress. This point is further reinforced by the study of 12 cities in middle income countries, where thresholds above which cold-related mortality occurred ranged from -3 to $28^{\circ} \mathrm{C}$, and the heat thresholds were 16-31 ${ }^{\circ} \mathrm{C}$. (Wilkinson et al. 2002) Additionally, typical homes in Mexico lack heating and air conditioning, and this lack of adequate temperature control may be more prevalent among the more disadvantaged sectors.

The pattern of differing associations between causespecific mortality and cold temperature by age in Mexico was different than that observed in Brazil, where respiratory disease mortality was more affected by cold temperatures among the elderly than was all-cause mortality (Gouveia et al. 2003). Our results also differ from those observed in 12 USA cities where cold temperatures had little effect on respiratory-cause mortality (Braga et al. 2002). Further investigation of the patterns we observed with more specific diagnoses of cause of death may provide insights as to mechanism.

One of the strengths of our study is the use of AT, a construct which characterizes the physiological experience better than just air temperature alone. Ideally, additional meteorological data (such as cloud cover, wind speed, and other parameters) would be used to better describe the exposure (Hoeppe 1999), but these are not routinely collected by the city monitoring networks.

Another important feature of this analysis is the inclusion of $\mathrm{O}_{3}$ as a covariate. Some reports of associations between temperature and mortality have not controlled for effects of any air pollutants (Braga et al. 2001; Curriero et al. 2002), though some included airborne particles (Wilkinson et al. 2002; O'Neill et al. 2003), and one controlled for several pollutants simultaneously but did not report unadjusted results (Gouveia et al. 2003). $\mathrm{O}_{3}$ has been associated with daily mortality in many geographical regions (Thurston and Ito 2001) and is correlated with temperature. Therefore, an understanding of the extent to which $\mathrm{O}_{3}$ levels, in addition to airborne particles, may be confounding temperature and mortality associations is an important contribution of this work and may be worth considering for other analyses. The Pearson's correlations of temperature and $\mathrm{O}_{3}$ were 0.46 in Mexico City and 0.08 in Monterrey from May to September ("summer") and, during the remainder of the year, 0.14 in Mexico City and 0.39 in Monterrey. Temperature and $\mathrm{PM}_{10}$ correlations were 0.42 (summer) and 0.04 (rest of year) in Mexico City and 0.29 (summer), 0.14 (rest of year) in Monterrey. While all these correlations were significant, they were relatively low, so the fact that we observed substantial confounding by these parameters suggests that the potential for such confounding is strong in many other locations. 
One interesting feature of the results is that control for pollutants and respiratory epidemics affected the temperature-effect estimates in different directions, depending on city and age group. As expected, in Monterrey, heat effects were relatively unconfounded by epidemics, but control for pollution did pull down the effect. Cold effects in Monterrey were affected in opposite directions for elderly and all-age mortality compared with child mortality. Given the wide confidence intervals for all these estimates, it is impossible to determine whether these patterns are true differences or statistical artifacts. However, children's exposure to temperature, pollution and response to respiratory epidemics may differ systematically from adults, resulting in different patterns of association for these exposures. In Mexico City, where statistical power for the data is greater, epidemics were an important confounder of cold-related mortality among children. Surprisingly, adjustment for epidemics slightly increased cold-related effects among all-age and elderly. Here again, these differences may be related to differences in exposure patterns or susceptibility among children. Pollution was not an important confounder of cold-related effects in any of the groups.

Longer-term seasonal trends in mortality are also important potential confounders of studies of temperature and daily mortality. Seasonal trends in mortality may be due to several factors, in addition to weather. The objective of the present study was to quantify the excess mortality associated with extreme temperature in the short term, and ensure that this estimate was not confounded by other determinants of mortality, including season. Choice of method for seasonal control is not purely a statistical issue, so evaluating the extent to which varying degrees of seasonal control changes affect estimates is important for enhancing confidence in the model results. In the present example, halving the $d f$ for the seasonal spline introduced substantial confounding of both the cold and heat effects. Under-control for season resulted in an approximately twofold underestimate of the heat effect in Monterrey. The confounding of the cold effect was in the opposite direction for both Mexico and Monterrey. With half the $d f$, the estimate was doubled in both cities. By contrast, when the $d f$ were doubled, heat and cold effects differed little from those derived from the base model, in which the seasonal spline $d f$ were chosen with standard techniques. This suggests that the base model spline adequately captured long-term variation in mortality and additional flexibility did not substantially change our ability to control for these trends.

One limitation of our work is the lack of hospital admissions data to characterize respiratory epidemic periods. Future efforts could assess the validity of substituting respiratory-cause mortality for hospital admissions to control for this important potential confounder. As was seen in Mexico City, respiratory epidemics among children explain a substantial portion of the daily mortality excess in this population group on cold days, and this phenomenon is likely to occur in other regions.

The present analysis provides further evidence of health effects on extreme temperature days, the number of which are likely to increase as a result of global climate change. The associations we observed in Mexico City and Monterrey remained positive and significant, even when other determinants of daily mortality, including air pollution, respiratory epidemics and varying ways of modeling seasonal patterns, were incorporated in the analyses. Further examination of these associations among low to middleincome countries such as Mexico, including evaluation of cause-specific mortality and socio-economic variables, will contribute to growing knowledge of the health impacts of climate change among highly populated and potentially vulnerable parts of the world.

Acknowledgements This publication was made possible in part by grant number 2 T32 ES07069 from the National Institute of Environmental Health Sciences (NIEHS), National Institutes of Health $(\mathrm{NIH})$. Its contents are solely the responsibility of the authors and do not necessarily represent the official views of the NIEHS, NIH. Additional funding sources include grants from NIEHS ES00002, and EPAR827353, the UK Medical Research Council G9900947, the Mellon Foundation, the Robert Wood Johnson Foundation Health and Society Scholars Program, University of North Carolina Institute of Latin American Studies, the Fulbright program, and in-kind assistance from the Centro Nacional de Salud Ambiental, Metepec, Mexico.

\section{References}

Basu R, Samet J (2003) The relationship between elevated ambient temperature and mortality: a review of the epidemiologic evidence. Epidemiol Rev 24:190-202

Borja-Aburto VH, Loomis DP, Bangdiwala SI, Shy CM, RasconPacheco RA (1997) Ozone, suspended particulates, and daily mortality in Mexico City. Am J Epidemiol 145:258-268

Braga AL, Zanobetti A, Schwartz J (2000) Do respiratory epidemics confound the association between air pollution and daily deaths? Eur Respir J 16:723-728

Braga AL, Zanobetti A, Schwartz J (2001) The time course of weather related deaths. Epidemiology 12:662-667

Braga ALF, Zanobetti A, Schwartz J (2002) The effect of weather on respiratory and cardiovascular deaths in 12 U.S. cities. Environ Health Perspect 110:859-863

Brumback BA, Ryan LM, Schwartz J, Neas LM, Stark PC, Burge HA (2000) Transitional regression models with application to environmental time series. J Am Stat Assoc 95:16-28

Curriero FC, Heiner KS, Samet JM, Zeger SL, Strug L, Patz JA (2002) Temperature and mortality in 11cities of the eastern United States. Am J Epidemiol 155:80-87

Dominici F, McDermott A, Zeger SL, Samet JM (2002) On the use of generalized additive models in time-series studies of air pollution and health. Am J Epidemiol 156:193-203

Easterling DR, Meehl GA, Parmesan C, Changnon SA, Karl TR, Mearns LO (2000) Climate extremes: observations, modeling, and impacts. Science 289:2068-2074

Gouveia N, Hajat S, Armstrong B (2003) Socio-economic differentials in the temperature-mortality relationship in Sao Paulo, Brazil. Int J Epidemiol 32

Hajat S, Kovats RS, Atkinson RW, Haines A (2002) Impact of hot temperatures on death in London: a time series approach. J Epidemiol Community Health 56:367-372

Hastie TJ, Tibshirani RJ (1990) Generalized additive models. Chapman and Hall, London

Health Effects Institute (2003) Special report: revised analyses of time-series studies of air pollution and health. Health Effects Institute, Boston, MA http://www.healtheffects.org/ Pubs/TimeSeries.pdf 
Hoeppe P (1999) The physiological equivalent temperature-a universal index for the biometeorological assessment of the thermal environment. Int J Biometeorol 43:71-75

Houghton JT, Ding Y, Griggs DJ, Noguer M, van der Linden PJ, Xiaosu D (eds) (2001) Climate Change 2001: The Scientific Basis. Contribution of Working Group I to the Third Assessment Report of the Intergovernmental Panel on Climate Change (IPCC). Cambridge University Press, UK

INEGI (2004) http://www.citypopulation.de. Vol. original source: http://www.inegi.gob.mx/inegi/default.asp. Thomas Brinkhoff

Kalkstein LS, Valimont KM (1986) An evaluation of summer discomfort in the United States using a relative climatological index. Bull Am Meteorol Soc 67:842-848

Karl TR, Knight RW, Plummer N (1995) Trends in high-frequency climate variability in the twentieth century. Nature 377:217220

Katsouyanni K, Zmirou D, Spix C, Sunyer J, Schouten JP, Ponka A, Anderson HR, Le Moullec Y, Wojtyniak B, Vigotti MA, Bacharova L, Schwartz J (1997) Short-term effects of air pollution on health: a European approach using epidemiologic time series data. The APHEA Project. Air Pollution Health Effects-A European Approach. Public Health Rev 25:7-18; discussion 19-28

Keatinge WR, Donaldson GC, Cordioli E, Martinelli M, Kunst AE, Mackenbach JP, Nayha S, Vuori I (2000) Heat related mortality in warm and cold regions of Europe: observational study. $\mathrm{Br}$ Med J 321:670-3

Klinenberg E (2002) Heat wave: A social autopsy of disaster in Chicago. University of Chicago Press, Chicago, Ill.

McCullagh P, Nelder JA (1989) Generalized linear models, 2nd edn. Chapman and Hall, London

O'Neill MS, Zanobetti A, Schwartz J (2003) Modifiers of the temperature and mortality association in seven U.S. cities. Am J Epidemiol 157:1074-1082
O’Neill MS, Loomis D, Borja-Aburto VH (2004) Ozone, area social conditions, and mortality in Mexico City. Environ Res 94(3):234-242

Patashnick H, Rupprecht EG (1991) Continuous PM-10 measurements using the tapered element oscillating microbalance. J Air Waste Manage 41:1079-1083

Romieu I, Ramirez-Aguilar M, Moreno-Macias H, BarrazaVillarreal A, Miller P, Hernandez-Cadena L, Carbajal-Arroyo LA, Hernandez-Avila M (2004). Infant mortality and air pollution: modifying effect by social class. Journal of Occupational \& Environmental Medicine 46(12):1210-1216

Semenza JC, Rubin CH, Falter KH, Selanikio JD, Flanders WD, Howe HL, Wilhelm JL (1996) Heat-related deaths during the July 1995 heat wave in Chicago. New Engl J Med 335:84-90

Semenza JC, McCullough JE, Flanders WD, McGeehin MA, Lumpkin JR (1999) Excess hospital admissions during the July 1995 heat wave in Chicago. Am J Prev Med 16:269-77

Steadman RG (1979) The assessment of sultriness. Part II. Effects of wind, extra radiation and barometric pressure on apparent temperature. J Appl Meteorol 18:874-885

Thurston GD, Ito K (2001) Epidemiological studies of acute ozone exposures and mortality. J Exp Anal Environ Epidemiol $11: 286-294$

Website Met-One (accessed April 7, 2004) http://www.metone.com/

Whitman S, Good G, Donoghue ER, Benbow N, Shou W, Mou S (1997) Mortality in Chicago attributed to the July 1995 heat wave. Am J Public Health 87:1515-1518

Wilkinson P, McMichael T, Kovats S, Pattenden S, Hajat S, Armstrong B (2002) International study of temperature and heatwaves on urban mortality in low and middle income countries (ISOTHURM). Epidemiology 13:S81

Wypij D (1996) Spline and smoothing approaches to fitting flexible models for the analysis of pulmonary function data. Am J Resp Crit Care 154:S223-S228 